\title{
Peer assessment als complexe vaardigheid
}

\author{
D. Sluijsmans
}

\section{Samenvatting}

Inleiding: Studenten vinden het vaak moeilijk om elkaar te beoordelen. Voor peer assessment hebben zij behoefte aan training in beoordelingsvaardigheden. Bij de Faculteit Onderwijs van de Hogeschool Limburg is een dergelijke training opgezet en onderzocht.

Trainingsopzet: De training werd ingebed in het bestaande onderwijs en omvatte: het definiëren van criteria, het beoordelen van de prestatie van een medestudent, het geven van constructieve feedback. Voor elke vaardigheid werden peer-assessmenttaken ontworpen, die de studenten tijdens het onderwijs uitvoerden. De trainingsresultaten werden beoordeeld door een schriftelijk peer assessment van de studenten te toetsen aan criteria voor peer assessment. Ook werd gekeken naar de prestaties op inhoudsgebonden producten, een door de studenten ingevulde vragenlijst en interviews met studenten en docenten.

Effecten van de training: Na de training waren de studenten beter in staat de prestaties van medestudenten te toetsen aan inhoudelijke criteria. Een bijkomend resultaat was dat studenten beter presteerden op de te beoordelen onderwijsonderdelen. Studenten stonden positiever tegenover peer assessment. Docenten gingen zich herbezinnen op hun eigen beoordelingsstrategieën. Richtlijnen: Aan het onderzoek zijn enkele richtlijnen voor peer assessment ontleend: het is vooral een leeractiviteit; studenten hebben begeleiding nodig; stel van tevoren samen met studenten beoordelingscriteria op; stimuleer interactie tussen studenten; begin in het eerste jaar, teneinde vooroordelen over beoordeling te bestrijden; vermijd oneigenlijk gebruik (bijvoorbeeld verlichting docententaak); kijk naar de voorbeeldfunctie van docenten.

Conclusie: Training in beoordelingsvaardigheden is leerzaam voor studenten. Na afloop staan zij positiever tegenover peer assessment. Door een training worden docenten en studenten zich beter bewust van alle aspecten van beoordeling. (Sluijsmans D. Peer assessment als complexe vaardigheid. Tijdschrift voor Medisch Onderwijs 2002;21(4):167-172.)

\section{Inleiding}

Het hoger onderwijs toont een groeiende belangstelling voor alternatieve vormen van assessment waarbij studenten een rol spelen, zoals self- en peer assessment. ${ }^{1} 2$ De geneeskundestudie en andere gezondheidszorgopleidingen zijn zeer geschikt voor onderzoek naar dergelijke nieuwe beoordelingsmethoden en betrokkenheid van studenten. Als toekomstige professionals moeten de studenten die deze opleidingen volgen, in staat zijn om kritisch naar zichzelf en het werk van medestudenten - en later collega's - te kijken.
Een manier om studenten te laten participeren in beoordelingsprocedures is peer assessment. Hierbij is de student verantwoordelijk voor het kritisch beoordelen van de werkzaamheden of prestaties van een medestudent op basis van passende standaarden. Peer assessment is geen toetsvorm. Het is een aanduiding van een vorm van beoordelen waarbij een belangrijke rol is weggelegd voor de student. Peer assessment is overigens niet beperkt tot studenten. Iedere vorm van beoordeling waarbij collega's elkaar beoordelen valt onder de noemer peer assessment. Zo 
kan peer review, dat gebruikelijk is bij veel wetenschappelijke tijdschriften, ook gezien worden als peer assessment.

Uit onderzoek blijkt dat bij peer assessment op dit moment veelal gebruik wordt gemaakt van speciaal ontworpen criterialijsten en Likertschalen. Ook blijkt dat studenten het moeilijk vinden om een betrouwbare beoordeling van elkaar te geven. ${ }^{3}$ Ze voelen zich er soms ongemakkelijk bij. ${ }^{5}$ Studenten blijken typische beoordelaarsfouten te maken, zoals 'friendship marking'. ${ }^{6}$ De kwantitatieve scores die studenten aan elkaar geven, leveren weinig informatie op over de manier waarop studenten tot een oordeel komen. In de literatuur is bovendien weinig te vinden over de strategieën die studenten hanteren bij het beoordelen van hun eigen werk of dat van medestudenten.

Uit vooronderzoek is gebleken dat studenten behoefte hebben aan oefening in het beoordelen van elkaar, voordat ze begrijpen wat hun rol is in het beoordelingsproces. ${ }^{7}$ Door meer instructie vooraf zouden studenten het nut van peer assessment beter gaan inzien. Peer assessment is een complexe vaardigheid die meer inhoudt dan het invullen van scores op een lijst met criteria en die getraind en getoetst moet worden. Daarom is in 1998 een promotieproject opgestart met als doel antwoord te geven op de vraag of studenten getraind kunnen worden in beoordelingsvaardigheid en - in bredere zin wat dit betekent voor het ontwikkelen van onderwijs.

De onderzoekscontext werd geboden door de Faculteit Onderwijs van de Hogeschool Limburg. Deze faculteit wilde onderwijsmodules op een andere wijze ontwerpen en studenten een actieve rol geven in de vorm van peer assessment. In het kader van het onderzoeksproject zijn drie experimenten uitgevoerd om te onderzoeken hoe een training in peer-assess- mentvaardigheden kan worden vormgegeven. In de eerste twee experimenten is gewerkt met een pretest-posttest control group design, dat wil zeggen dat de helft van de groep studenten een training kreeg en de andere helft niet. Dit onderzoek werd gedaan in een tweedejaars module van zes weken. In het derde experiment is een grote groep eerstejaars studenten longitudinaal getraind in peer-assessmentvaardigheden. Geïnteresseerden kunnen de verslagen van deze onderzoeken opvragen bij de auteur.

Bij elk experiment is onderzocht welke effecten een training in peer assessment heeft op:

1. de beoordelingsvaardigheid van studenten;

2. de inhoudelijke prestaties op de in de training beoordeelde onderwijsonderdelen;

3. de percepties van studenten en docenten.

In dit artikel wordt de opzet van de peerassessmenttraining beschreven en worden de onderzoeksbevindingen gerapporteerd. Ten slotte wordt een aantal praktische richtlijnen gegeven voor het toepassen van peer assessment (training).

\section{De opzet van een training in peer assess- ment}

Bij het onderzoek is ervan uitgegaan dat er voor peer assessment vaardigheden nodig zijn waarbij studenten moeten worden ondersteund. Een ander uitgangspunt was dat deze ondersteuning moet worden ingebed in bestaande onderwijsinhoud, aangezien studenten elkaar beoordelen op producten die nauw met de inhoud samenhangen. In het onderzoeksproject is samen met de betrokken docenten gewerkt aan het ontwerp van een training die aansloot bij de onderwijsinhoud.

Het doel van de training was dat de studenten die de training hadden gevolgd 
na afloop van een onderwijsonderdeel in staat waren op verantwoorde wijze een product of prestatie van een medestudent kritisch te beoordelen op basis van relevante criteria. Nagegaan is wat het precies betekent om een medestudent te beoordelen. Hiertoe is de vaardigheid die nodig is voor peer assessment met behulp van 'skill decomposition' opgesplitst in onderdelen. ${ }^{8}$ Dit resulteerde in drie hoofdvaardigheden: 1) het definiëren van criteria; 2 ) het beoordelen van de prestatie van een medestudent; en 3) het geven van constructieve feedback, gericht op het toekomstig leren. Uitgaande van deze drie hoofdvaardigheden is een peer-assessmenttraining ontwikkeld. Hiervoor zijn de deelvaardigheden geoperationaliseerd in concrete activiteiten, de peer-assessmenttaken. Deze peer-assessmenttaken dienden verweven te worden met het bestaande onderwijs. Zo is een taak ontworpen rondom het definiëren van criteria. Studenten moesten kennis opdoen over wat valide criteria zijn en hoe je ze operationaliseert. In deze taak hebben studenten onderhandeld met de docent over de criteria waaraan een eindproduct, bijvoorbeeld een lesplan dat ze aan het eind van een module moesten inleveren, moest voldoen. In een andere peer-assessmenttaak hebben studenten met de docent gediscussieerd over constructieve vormen van feedback en hoe je op een goede manier feedback geeft aan je medestudent.

Nadat ze alle peer-assessmenttaken voltooid hadden, moesten studenten voldoende informatie hebben vergaard om een echt peer assessment uit te kunnen voeren. Bij elk experiment in het kader van het onderzoek hebben de studenten aan het einde van de betreffende onderwijsperiode een schriftelijke peer-assessmentrapportage ingeleverd. Hiervoor werd een blanco peer-assessmentformulier gebruikt. Alle assessmentrapportages van de studen- ten zijn geanalyseerd met behulp van een beoordelingsformulier. Op dit beoordelingsformulier stonden alle criteria waaraan een goede peer-assessmentrapportage moet voldoen, zoals het benoemen van de productgebonden inhoudelijke criteria die door de studenten in de peer-assessmenttaken waren opgesteld en het geven van constructieve suggesties.

Om te onderzoeken of de beoordelingsvaardigheid na de training was verbeterd, zijn de effecten van de training gemeten met behulp van de volgende gegevens:

- een kwalitatief peer-assessmentrapport: de schriftelijke beoordeling die elke student heeft gegeven van de prestatie van een medestudent op grond van de kennis opgedaan in de peer-assessmenttaken;

- de prestaties op de inhoudsgebonden producten;

- de resultaten van de vragenlijst die voor en na de training door de studenten is ingevuld;

- interviews met studenten en docenten.

\section{De effecten van training in peer assessment}

Studenten bleken na de training inderdaad beter in staat te zijn inhoudelijke criteria te herkennen in de prestaties van hun medestudenten. Daarbij moet worden aangetekend dat dit ook vooral te danken was aan de nieuwe structuur van het onderwijs waarbij toetsing en onderwijs volledig op elkaar zijn afgestemd en in elkaar overgaan. In de peer-assessmenttaken die tijdens de onderwijstaken zijn uitgevoerd, hebben de studenten geleerd hoe ze de criteria waaraan het gewenste gedrag moest voldoen, konden herkennen en beschrijven. Na het afronden van de peer-assessmenttaken hadden de studenten niet alleen een overzicht van de beoordelingscriteria, maar ook richtlijnen voor het geven van feedback en het 
schrijven van een assessmentrapport. Op deze wijze leerden de studenten niet alleen een cijfer te geven, maar ook te beargumenteren hoe ze tot een oordeel waren gekomen. Een leerervaring die vooral voor henzelf heel nuttig was.

Een andere belangrijke bevinding is dat de studenten zelf ook beter presteerden op het te beoordelen gedrag. Dit voegt een grote meerwaarde toe aan een training in beoordelingsvaardigheden. Bij een training vergaren de studenten niet alleen kennis over het beoordelen en het geven van feedback, maar zij zijn ook heel bewust bezig met de inhoud van de taak of de vaardigheid die zij moeten beoordelen, waardoor zijzelf daarop beter presteren.

Het onderzoek had ook als resultaat dat studenten positiever zijn gaan denken over peer assessment en hun rol binnen het onderwijs. Het ontwikkelen van peerassessmentvaardigheden bleek overigens sterk af te hangen van de wijze waarop studenten elkaar moesten beoordelen. In de experimenten was de beoordelingssituatie vrij open. Studenten rapporteerden in aanwezigheid van elkaar mondeling over de schriftelijke beoordelingen. Enkele studenten gaven aan dat ze graag wilden beoordelen, maar aanvankelijk liever in een meer 'gesloten' omgeving, waarin de anonimiteit beter gewaarborgd is. Zeker wanneer het allemaal nog nieuw is.

Tot slot is gebleken dat het invoeren van peer assessment en peer-assessmenttaken een aanzienlijke investering van de betrokken docenten vereist. Het ontwerpen van de training en het inbedden van de peerassessmenttaken in bestaande modules betekende een herbezinning op deze modules. Ook beseften de docenten hoe complex beoordelen is. Discussies tijdens de ontwerpfase van de training brachten aan het licht dat docenten allemaal hun eigen beoordelingsstrategieën hanteren, zonder dat zij daar echt voor zijn opgeleid.

\section{Richtlijnen voor implementatie}

In het onderstaande worden enkele tips gegeven die bij het nadenken over peer assessment een helpende hand kunnen bieden.

De eerste handreiking is dat peer assessment bovenal als een leeractiviteit moet worden beschouwd, niet als toetsvorm. Studenten kunnen bijvoorbeeld elkaar beoordelen op de vaardigheid 'het voeren van een intake-gesprek met een patiënt'. De toetsvorm is een gesprek met een simulatiepatiënt en peer assessment betekent dat studenten een rol hebben in het beoordelingsproces.

Vervolgens moeten studenten worden begeleid in de vaardigheden die nodig zijn voor peer assessment. Zogenaamde peerassessmenttaken, die systematisch zijn ingebed in het bestaande onderwijs, zorgen ervoor dat studenten tijdig betrokken worden bij de beslissingen die van belang zijn voor het beoordelen van elkaar. Studenten worden zich geleidelijk aan bewust van hun rol. De docent of de tutor speelt een belangrijke coachende rol in de begeleiding van studenten naar het zelfstandig nemen van beslissingen ten aanzien van hun eigen leerproces.

Ook is het van groot belang dat criteria die gebruikt worden bij peer assessment van tevoren worden vastgesteld. In overleg met de studenten moet afgesproken worden aan welke eisen het te beoordelen product of proces moet voldoen. Criteria kunnen worden gedefinieerd als richtlijnen, regels, karakteristieken of dimensies die worden gehanteerd om de kwaliteit van een bepaalde prestatie te meten. Criteria bevatten informatie over het product dat wordt beoordeeld en het niveau dat in dat product of gedrag wordt nagestreefd. Het definiëren van criteria is eerder in deze bijdrage als één van de drie vaardigheden beschreven die aan de orde kwamen in de training in peer assessment. 
Een volgende richtlijn is om in de peerassessmenttaken zoveel mogelijk interactieve reflecties tussen studenten te stimuleren, bijvoorbeeld bij het definiëren van criteria. De docent vervult de rol van coach. Hij/zij stelt de juiste vragen en stuurt de discussies, maar geeft niet zelf de goede antwoorden. Van belang is dat iedere student in de groep een bijdrage levert en dat er een wederzijdse afhankelijkheid tussen studenten ontstaat. Hierdoor is het mogelijk dat studenten niet meer op basis van de aanwezigheidsplicht deelnemen aan de groep, maar op grond van het feit dat zij elkaar iets geven en daarvoor in ruil van elkaar iets ontvangen. Bij elke peer-assessmenttaak speelt samenwerkend leren en sociale interactie een belangrijke rol.

Een suggestie is om meteen in het eerste jaar te starten met peer-assessmentactiviteiten. Observaties tijdens de experimenten in het onderzoek brachten aan het licht dat veel studenten vanuit het voortgezet onderwijs vooroordelen hebben over onderwijs, toetsing en de rol van studenten en docenten daarin. Studenten zijn snel geneigd de docent te zien als expert en als degene die beoordeelt. Wanneer studenten van meet af aan de gelegenheid krijgen op basis van geldige argumenten mee te denken over onderwijs en toetsing, zal dit leiden tot een herziening van dit beeld. De docent blijft weliswaar de expert, maar dit wordt meer gezien vanuit een coachend perspectief.

Ook dient men goed te overwegen voor welke doeleinden peer assessment wordt ingezet. Oneigenlijk gebruik van peer assessment moet worden voorkomen. Een oneigenlijk argument voor de invoering van peer assessment is bijvoorbeeld de verlaging van de beoordelingslast van docenten. Hoewel dit vanuit organisatorisch perspectief een logisch argument kan lijken, draagt het weinig bij aan het leren van de studenten.
Ten slotte speelt het probleem dat studenten in het hoger onderwijs geacht worden zich allerlei vaardigheden eigen te maken, maar dat het wellicht aanbeveling zou verdienen eerst aandacht te besteden aan het goede voorbeeld dat onderwijsgevenden kunnen geven. Te denken valt hierbij aan de specialist in het ziekenhuis die arts-assistenten moet begeleiden en coachen in het opdoen van medische vaardigheden, maar die er, bijvoorbeeld door ervaringen in de eigen opleiding, het idee op nahoudt dat de arts-assistent het vooral op eigen kracht zelf moet leren.

\section{Conclusie}

Het aanbieden van ander onderwijs en een andere manier van toetsing vragen een andere houding van zowel studenten als docenten. Docenten worden gedwongen zichzelf een spiegel voor te houden en goed na te denken over de manier waarop ze studenten willen beoordelen. Studenten moeten aanvaarden dat de docent niet de enige beoordelingsinstantie is, maar dat zij ook zelf een eigen visie moeten ontwikkelen en kunnen meebepalen wat belangrijk is. Dit betekent niet dat de studenten aan hun lot worden overgelaten. Er zullen altijd duidelijke richtlijnen moeten worden geformuleerd en de studenten moet worden geleerd om goed te kunnen beoordelen. ${ }^{9}$ Daarbij zal de docent als het ware over de schouder mee blijven kijken.

Uit de resultaten van onderzoek naar de effecten van peer-assessmenttraining blijkt dat niet alleen de studenten beter hebben leren beoordelen, maar dat ook de betrokken docenten beter zijn gaan kijken naar die aspecten van het te beoordelen onderwijsresultaat die werkelijk relevant zijn voor de beroepspraktijk en die bovendien ook waarneembaar zijn of waarneembaar gemaakt kunnen worden. Beoordelingsvaardigheid is echter nog steeds het ondergeschoven 
kindje van de onderwijsfamilie. De uitgevoerde onderzoeken vormen weer een bewijs dat de staart van het onderwijs de beoordeling - bepalend is voor het onderwijssucces.

\section{Literatuur}

1. Sluijsmans D, Dochy F, Moerkerke G. Creating a learning environment by using self- peer- and coassessment. Learning Environments Research 1999;1:293-319.

2. Boud D. Enhancing learning through self assessment. London: Philadelphia: Kogan Page; 1995.

3. Falchikov N. Peer feedback marking: Developing peer assessment. Innovations in Education and Training International 1995;32(2):175-87.

4. Freeman M. Peer assessment by groups of group work. Assessment and Evaluation in Higher Education 1995;20:289-300.

5. Pâquet MR, Des Marchais JE. Students' acceptance of peer assessment. Education for Health 1998;11:25-35.
6. Pond K, Ul-Haq R, Wade W. Peer review: a precursor to peer assessment. Innovations in Education and Training International 1995;32:31423.

7. Sluijsmans D, Moerkerke G, Dochy F, Merriënboer $\mathrm{J}$ van. Peer assessment in problem based learning. Studies in Educational Evaluation 2001;27(2):15373.

8. Merriënboer J van. Training complex cognitive skills. Englewood Cliffs, NJ: Educational Technology Publications; 1997.

9. Boud D, Falchikov N. Quantitative studies of selfassessment in higher education: a critical analysis of findings. Higher Education 1989;18:529-49.

\section{De auteur:}

Drs. Dominique Sluijsmans, is als assistent in opleiding verbonden aan het Onderwijstechnologisch Expertise Centrum van de Open Universiteit Nederland.

\section{Correspondentieadres:}

Dominique Sluijsmans, assistent in opleiding, Open Universiteit Nederland, OTEC, Postbus 2960, 6401 DL Heerlen,dominique.sluijsmans@ou.nl.

\section{Summary}

Introduction: Peer assessment is difficult for most students. They need guidance in assessing their fellow students' performance. A peer assessment course was implemented at the Faculty of Education of the Limburg School for Higher Vocational Training, the Netherlands.

Course design: The course was embedded in the regular curriculum and comprised: defining assessment criteria, assessing fellow students' performance, giving constructive feedback. Assignments were developed for every assessment skill. The outcomes of the course were measured by evaluating: whether students' written assessments met the criteria for peer assessment; students' results on course components used in peer assessment; a written questionnaire; and interviews with students and teachers.

Course effects: Students were better able to perform peer assessment using predefined criteria. An added effect was the improvement in students' performance on course components used to practise peer assessment. Students adopted a more positive attitude towards peer assessment. Teachers re-evaluated their own assessment strategies.

Guidelines: The following guidelines for peer assessment emerged from the course: peer assessment is primarily a learning activity; students need guidance; define assessment criteria together with the students before the actual assessment; stimulate interaction between students; start peer assessment from year 1 to combat prejudice regarding assessment; avoid improper use of peer assessment such as to relieve teachers' workloads; take account of the teacher as a role model.

Conclusion: A course in peer assessment is instructive. Students' attitudes towards peer assessment become more positive as a result of the course. The course increases teachers' and students' awareness of all aspects of assessment. (Sluijsmans D. Peer assessment as a complex skill. Dutch Journal of Medical Education 2002;21(4):167-172.) 